\title{
PEMBUATAN BASIS DATA SPASIAL NILAI TANAH \\ UNTUK MENGIDENTIFIKASI PERUBAHAN NILAI TANAH PADA TAHUN 2015-2016 \\ (Studi Kasus : Kecamatan Tuban, Kabupaten Tuban)
}

\author{
Yanto Budisusanto, Balqis Imania Nabilah, \\ Departemen Teknik Geomatika, Fakultas Teknik Sipil, Lingkungan dan Kebumian \\ Institut Teknologi Sepuluh Nopember (ITS) \\ Email: imania.nabilah@gmail.com; yanto_b@geodesy.its.ac.id
}

\begin{abstract}
Abstrak
Kecamatan Tuban merupakan salah satu Kecamatan di Kabupaten Tuban, Jawa Timur. Untuk memperlancar transportasi di Kecamatan Tuban direncanakan pengembangan jaringan jalan. Dengan adanya pengembangan jaringan jalan tersebut menyebabkan nilai tanah disekitarnya menjadi naik. Oleh karena itu dibutuhkan basis data nilai tanah yang sistematis sehingga dapat digunakan dalam penyelenggaraan layanan komputerisasi pertanahan. Layanan komputerisasi tersebut menyediakan informasi tentang nilai tanah berikut memberikan informasi tentang perubahannya. Disamping itu untuk kegiatan mendokumentasikan data nilai tanah menggunakan sistem basisdata inventarisasi nilai tanah sehingga pengelolaan data dan informasi nilai tanah menjadi lebioh efektif. Penelitian dilakukan dalam rangka membuat suatu basis data spasial yang dapat dimanfaatkan sebagai inventarisasi data nilai tanah sekaligus bahan pertimbangan untuk analisis perubahan nilai tanah yang berubah tiap tahunnya. Basisdata dibangun menggunakan teknologi Sistem Menejemen Basisdata (SMBD) PostgreSQL beserta ekstensinya PostGIS. Penelitian ini menggunakan data-data berupa data spasial berupa peta administrasi dan data non - spasial berupa data tabular zona nilai tanah. Perancangan basisdata dilakukan dengan beberapa tahapan yaitu perancangan model konseptual, model logika, dan model fisik hingga implementasi basis data. Basis data spasial yang terbentuk kemudian dilakukan uji transaksi basis data dengan query spasial basisdata di postgreSQL. Kemudian dilakukan validasi pada perangkat lunak pengolah data sistem informasi geografis dengan query yang sama. Sehingga terbentuk basis data spasial nilai tanah Kecamatan Tuban yang tervalidasi. Dari penelitian yang telah dilakukan, dapat disimpulkan bahwa penelitian ini berhasil membuat basis data spasial inventarisasi data nilai tanah. Basisdata yang telah dibuat dapat dijadikan sebagai data pendukung dalam mengidentifikasi perubahan nilai tanah di Kecamatan Tuban. Informasi nilai tanah terdapat perubahan nilai tanah disetiap zonanya dimana yang tertinggi yaitu pada zona 138 dengan perubahan sebesar Rp. 100.000,00 sedangkan zona yang tidak mengalami perubahan nilai tanah yaitu pada zona 122 dengan harga tanah tetap sebesar Rp 110.000,00.
\end{abstract}

Kata Kunci: nilai tanah, query spasial, PostgreSQL, PostGIS

\section{PENDAHULUAN}

Kecamatan Tuban merupakan salah satu Kecamatan di Kabupaten Tuban, Jawa Timur. Kecamatan Tuban telah direncanakan sebagai rencana pengembangan jaringan jalan nasional berdasarkan Peraturan Daerah No. 9 tahun 2012 dan Perda RTRW Kabupaten Tuban tahun 20122032 pada bab III pasal 17 disebutkan tentang rencana jaringan jalan outer ring road Kota Tuban melewati Kecamatan Palang -Kecamatan Semanding- Kecamatan Tuban -Kecamatan Merakurak- Kecamatan Jenu, sehingga dapat menyebabkan perubahan penggunaan lahan disekitar wilayah Kecamatan Tuban yang awalnya lahan pertanian menjadi lahan permukinan. Faktor ini mempengaruhi perubahan nilai tanah secara signifikan di daerah tersebut. Dengan adanya pengem-bangan jaringan jalan menyebabkan daya tampung nilai tanah menjadi kompleks di Kecamatan Tuban. Oleh karena itu dibutuhkan daya tampung dalam menghimpun basisdata nilai tanah yang sistematis sehingga dapat digunakan dalam penyelenggaraan layanan komputerisasi pertanahan. Layanan tersebut menyediakan informasi tentang perubahan nilai tanah dan untuk dokumentasi sistem basisdata inventarisasi nilai tanah. Kondisi yang demikian akan menjadi pengelolaan data dan informasi pertanahan menjadi lebih baik terkait perubahan nilai tanah disetiap tempat. Informasi tentang perubahan nilai tanah memegang peranan penting dalam kaitannya sebagai bahan yang mendasari proses analisis, penilaian, monitoring kebijakan nilai 
tanah. Salah satu wujud pengelolaan data dan informasi dalam perubahan nilai tanah yaitu pembangunan sistem informasi danmanajemen pertanahan yang mencakup berbagai kegiatan yang salah satunya adalah penyusunan basisdata spasial nilai tanah. Penyusunan basisdata spasial ini sebagai bahan perencanaan untuk meningkatkan pola penyusunan dan perubahan nilai tanah yang lebih sistematis serta updating data nilai tanah yang optimal melalui kegiatan inventarisasi.

Berdasarkan permasalahan ini, penelitian dilakukan dalam rangka membuat suatu basisdata spasial yang dapat dimanfaatkan sebagai inventarisasi data nilai tanah sekaligus untuk analisis perubahan nilai tanah yang terjadi tiap tahunnya. Basisdata spasial yang akan disusun menyediakan informasi mengenai data nilai tanah berdasarkan harga pasar wajar wilayah kecamatan Tuban kabupaten Tuban.

\section{METODE}

Peta Zona Nilai Tanah tahun 2015-2016, Peta Batas Administrasi, Data tabular Nilai Tanah tahun 2015-2016 Kecamatan Tuban, kabupaten Tuban dibuat basis data spasialnya menggunakan perangkat lunak open source PostgreSQL dengan ekstensi PostGIS. Perancangan Basis Data teridentifikasi atas 6 tabel entitas. Tabel entitas tersebut adalah tabel kecamatan, kelurahan, status, nilai tanah, zona 2016 dan zona 2015. Rancangan konseptual basisdata menggunakan pemodelan bahasa tingkat tinggi ERD (Entity Relationship Diagram) yang ditunjukkan pada Gambar 1 memiliki kerangka tabel sebagai berikut:

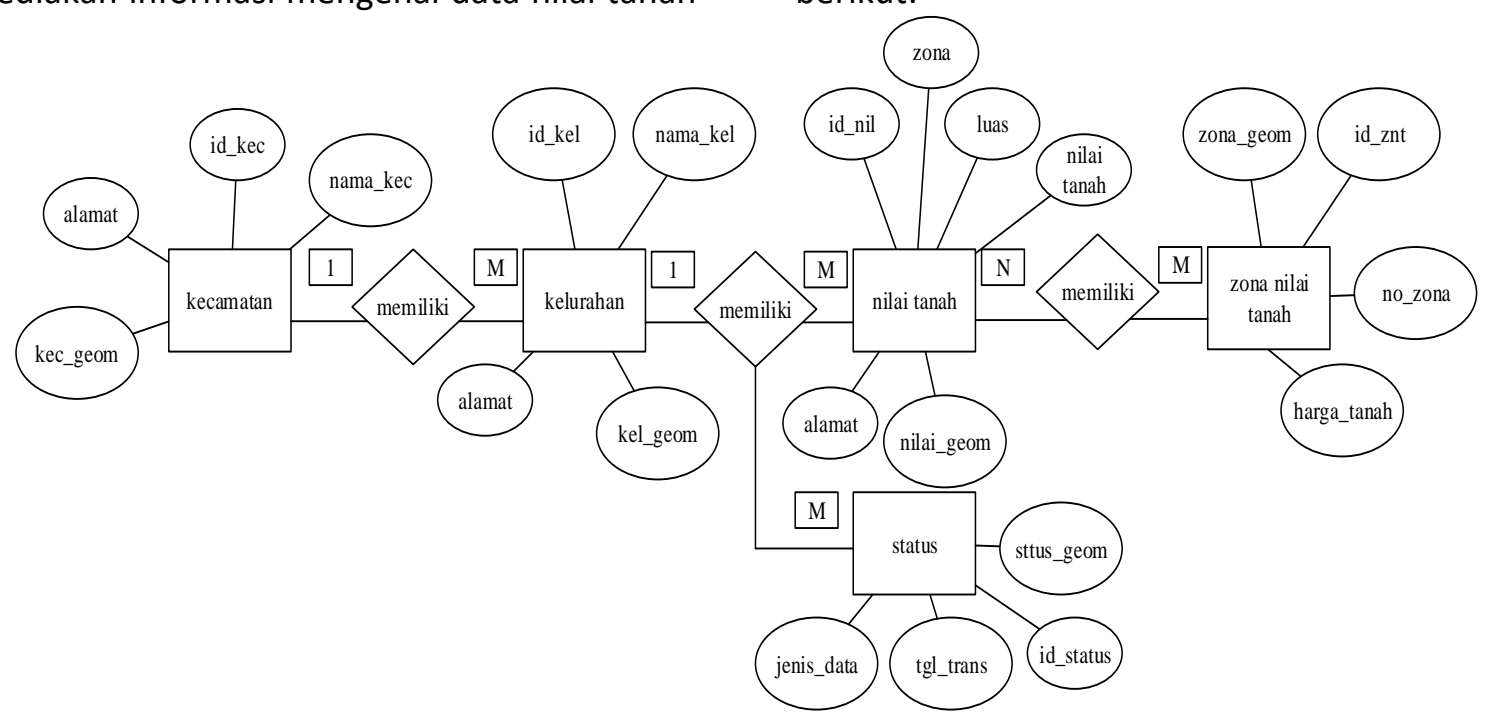

Gambar 1. Model Logika Basisdata

Secara sederhana Hubungan antar entitas tersebut akan dijelaskan dalam aturan sebagai berikut:

1. Entitas kecamatan memiliki derajat hubungan 1:m dengan entitas kelurahan, karena dalam satu kecamatan terdapat beberapa kelurahan.

2. Entitas kelurahan memiliki derajat hubungan 1:m dengan entitas status, karena didalam sebuah kelurahan terdapat beberapa bidang tanah yang memiliki beragam status kepemilikan tanah.
3. Entitas kelurahan memiliki derajat hubungan 1:m dengan entitas nilai tanah, karena didalam sebuah kelurahan terdapat beberapa nilai tanah.

4. Entitas nilai tanah memiliki derajat hubungan $\mathrm{m}: 1$ dengan entitas zona nilai tanah, karena beberapa zona nilai tanah merupakan pengelompokkan dari beberapa nilai tanah.

5. Entitas Zona Nilai Tanah memiliki derajat hubungan $m: n$ dengan entitas kelurahan, karena beberapa zona nilai tanah terdapat di lebih dari satu kelurahan, sedangkan dalam 
satu kelurahan terdiri lebih dari satu jenis zona nilai tanah.

Model logika basisdata yang ditunjukkan pada Gambar 2 dengan penjelasan sebagai berikut:

1. Satu Kecamatan terdiri dari beberpa kelurahan.
a. Tabel utama: kecamatan
b. Tabel kedua: kelurahan
c. Relationship: one-to-many (1:M)
d. Attribute penghubung: id_Kecamatan (FK id_kelurahan di kecamatan)

2. Satu kelurahan memiliki beberapa nilai tanah
a. Tabel utama: kelurahan
b. Tabel kedua: nilai tanah
c. Relationship: one-to-many (1:M)
d. Attribute penghubung: id_kelurahan (FK id_nilai di kelurahan)

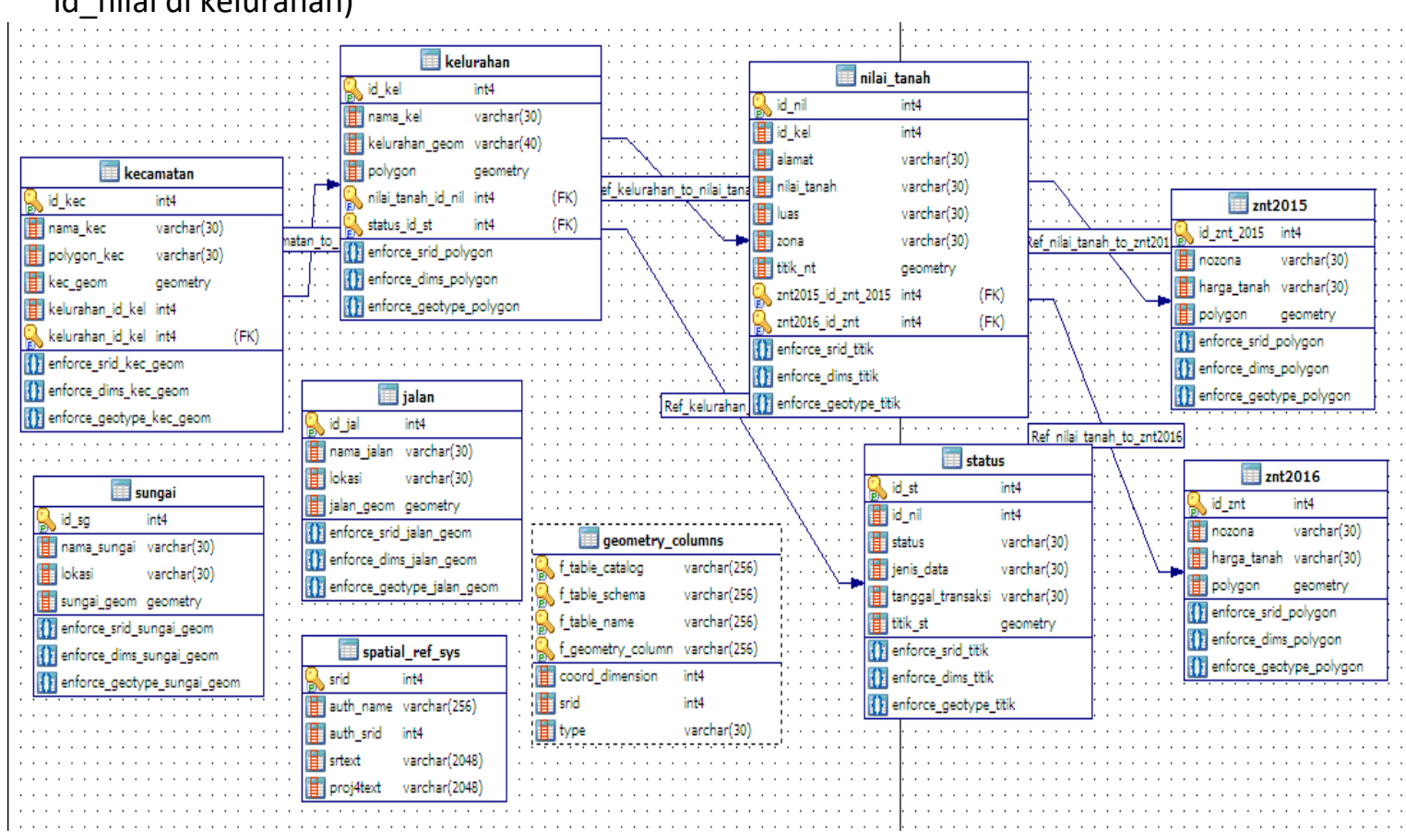

3. Satu kelurahan memiliki status kepemilikan tanah
a. Tabel utama: kelurahan
b. Tabel kedua: status
c. Relationship: one - to many (1:M)
d. Attribute penghubung: id kelurahan (FK id_status di keluahan)

4. Beberapa nilai tanah kelompokkan menjadi satu zona nilai tanah
a. Tabel utama: nilai tanah
b. Tabel kedua: zona nilai tanah (ZNT 2015/2016)
c. Relationship: many-to-many (M:N)
d. Attribute penghubung: id_nilai (FK id_znt di nilai tanah)

Gambar 2. Model Logika Basisdata

Dari model fisikal basisdata dan susunan struktur tabel dapat dilihat pada tabel 1. Bahwa yang menjadi identitas utama adalah: id_kec untuk tabel kecamatan, id_kel untuk tabel kelurahan, id_status untuk tabel status, id_nilai untuk tabel nilai tanah, dan id_zona untuk tabel zona 2015 dan zona 2016.

Implementasi Basisdata dibuat dengan menyusun beberapa berkas (file) dengan bahasa skrip (SQL) menggunakan perangkat lunak untuk mendisain sistem basis data. Dengan melakukan generate DDL (Data Definiton Language) secara otomatis tersusun skrip SQL yang siap dieksekusi pada perangkat lunak SMBD PostgreSQL. Basis data akan langsung terbentuk diperangkat lunak SMBD PostgreSQL dengan mengeksekusi pada jendela SQL editor. Selanjutnya dilakukan input data. 
Tabel 1. Perancangan Fisik Basisdata

\begin{tabular}{cllcll}
\hline Tabel & \multicolumn{1}{c}{ Field } & $\begin{array}{c}\text { Tipe } \\
\text { Data }\end{array}$ & $\begin{array}{c}\text { Lebar } \\
\text { Data }\end{array}$ & Konstrin & Key \\
\hline Kecamatan & id_kec & Integer & 10 & Not Null & PK \\
& nama_kec & Varchar & 20 & Not Null & \\
& alamat & Varchar & 20 & - & \\
& Kec_geom & Integer & 200 & Not Null & \\
Kelurahan & id_kel & Integer & 10 & Not Null & PK \\
& Nama_kel & Varchar & 15 & Not Null & \\
& alamat & Varchar & 20 & - & \\
& Kel_geom & Integer & 200 & Not Null & \\
Status & id_status & Integer & 10 & Not Null & PK \\
& Jenis_data & Varchar & 15 & - & \\
& Status_geom & Integer & 20 & Not Null & \\
& Tgl_trans & Varchar & 15 & - & \\
\hline
\end{tabular}

Lanjutan Tabel 1.

\begin{tabular}{clcccc}
\hline Tabel & \multicolumn{1}{c}{ Field } & $\begin{array}{c}\text { Tipe } \\
\text { Data }\end{array}$ & $\begin{array}{c}\text { Lebar } \\
\text { Data }\end{array}$ & Konstrin & Key \\
\hline Nilai Tanah & id_nilai & Integer & 10 & Not Null & PK \\
& Nilai_tanah & Varchar & 10 & Not Null & \\
& alamat & Varchar & 20 & - & \\
& Luas & Varchar & 10 & Not Null & \\
& Zona & Varchar & 10 & Not Null & \\
& Nilai_geom & Integer & 200 & - & \\
Zona & Id_zona & Integer & 10 & Not Null & PK \\
& No_zona & Varchar & 10 & Not Null & \\
& Harga_tanah & Varchar & 10 & Not Null & \\
& Zona_geom & Varchar & 200 & Not Null & \\
\hline
\end{tabular}

Uji transaksi basis data spasial dilakukan menggunakan perangkat lunak PostgreSQL dengan beberapa query yang diujikan baik query spasial maupun tabular. Hasil dari uji transaksi pada PostgreSQL dilakukan validasi apakah basis data spasial yang dibuat telah benar dengan query yang sama menggunakan perangkat lunak SIG.

\section{HASIL DAN PEMBAHASAN}

Berikut ini adalah salah satu contoh skrip SQL yang membentuk Tabel ZNT2016 adalah :

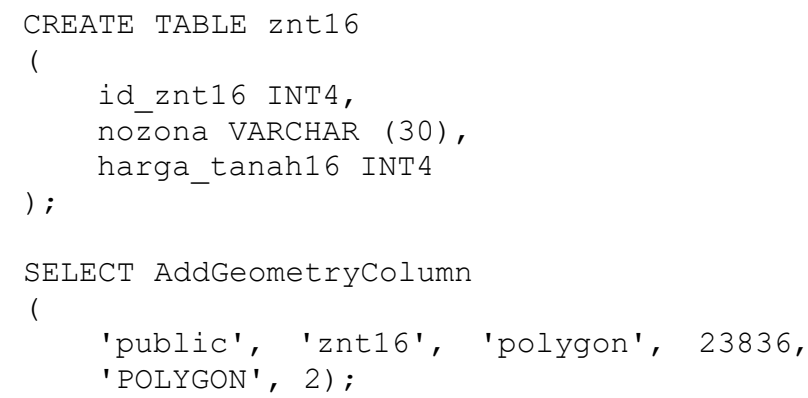

INSERT INTO znt16 VALUES

(

3695, 80, 310000, ST_GeomFromText ('POLYGON ((KOORDINAT)) ', 23836) ) ；

Hasil dari perintah SQL diatas adalah berupa tabeltabel yang masih kosong. Sedangkan perintah SQL untuk proses manipulasi dan transaksi data seperti: input atau penambahan data, pembaharuan data, pencarian atau seleksi data, dan penghapusan data, dikemas ke dalam file-file skrip tersendiri.

Gambar 3. menunjukkan hasil pembentukan tabel yang telah dibuat menggunakan perintah SQL. Selanjutnya akan dilakukan proses penambahan data sesuai dengan data yang dibutuhkan. Sedangan salah satu isian tabel dapat dilihat pada Gambar 4. Tabel ZNT 2016 yang berisi data tabular dan kolom geometri. Kolom data tabular yang memberikan informasi atribut dari kolom geometri. Kolom geometri adalah data yang akan divisualisasi melalui perangkat lunak berbasis SIG (Sistem Informasi Geografis).

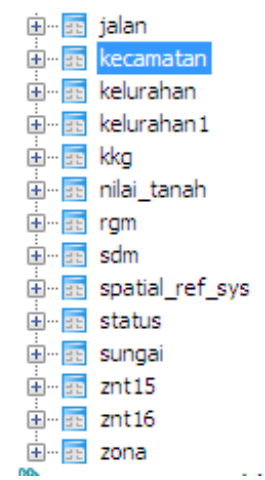

Gambar 3. Hasil Pembuatan Tabel pada PostgreSQL

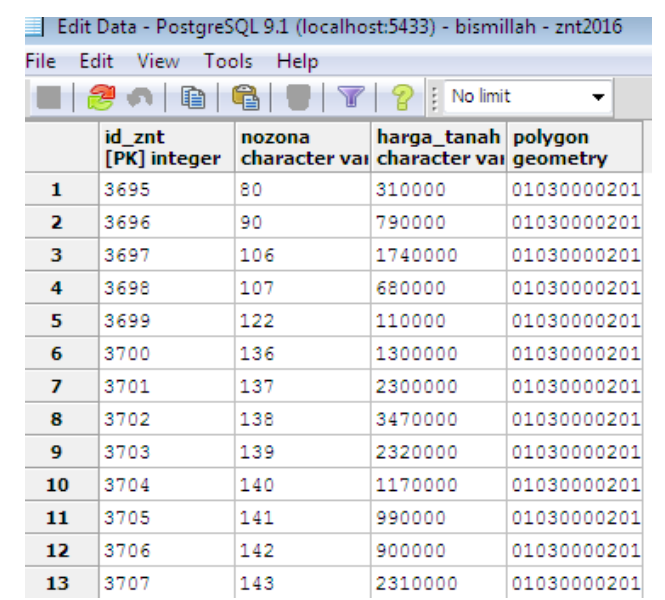

Gambar 4. Hasil Pengisian Record Tabel ZNT 2016 
Berikut beberapa query spasial yang diuji coba pada PostgreSQL dan validasi menggunakan perangkat lunak SIG adalah:

a. Menampilkan perubahan nilai tanah di Kecamatan Tuban (lihat Gambar 5 dan 6)

b. Menampilkan zona yang mengalami perubahan nilai tanah terbesar (lihat Gambar 7 dan 8). Dari hasil query diatas dapat dilihat pada output pane bahwa zona yang mengalami perubahan nilai tanah lebih dari Rp 70.000,- yaitu zona 138 dengan besar perubahan Rp 100.000,- dari tahun 2015 hingga tahun 2016.

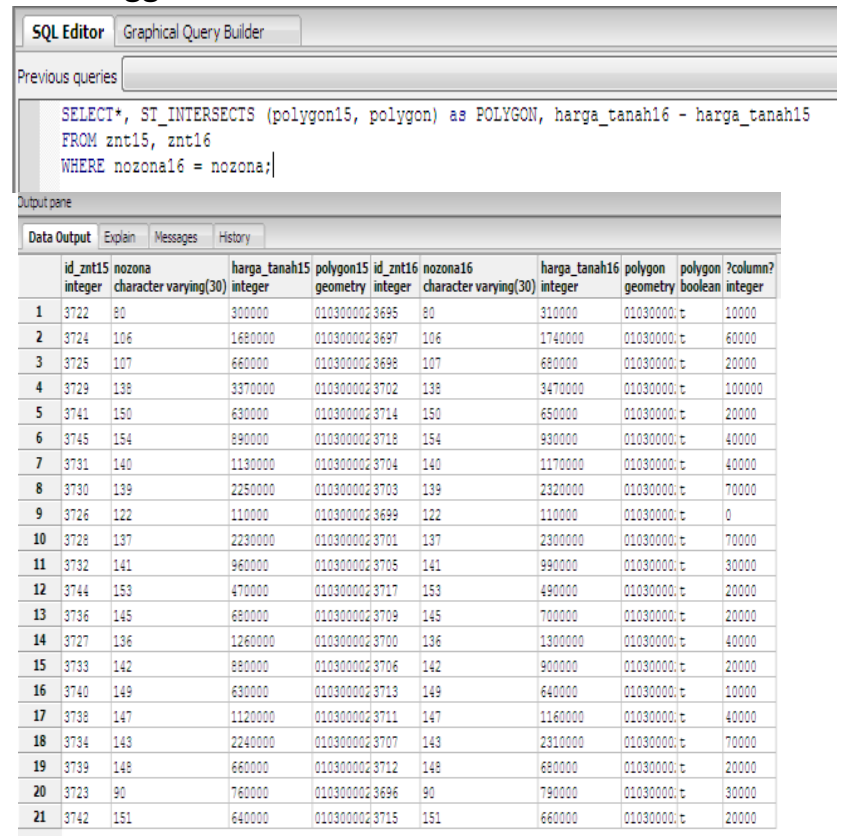

Gambar 5. Hasil Query Selisih Pada PostgreSQL

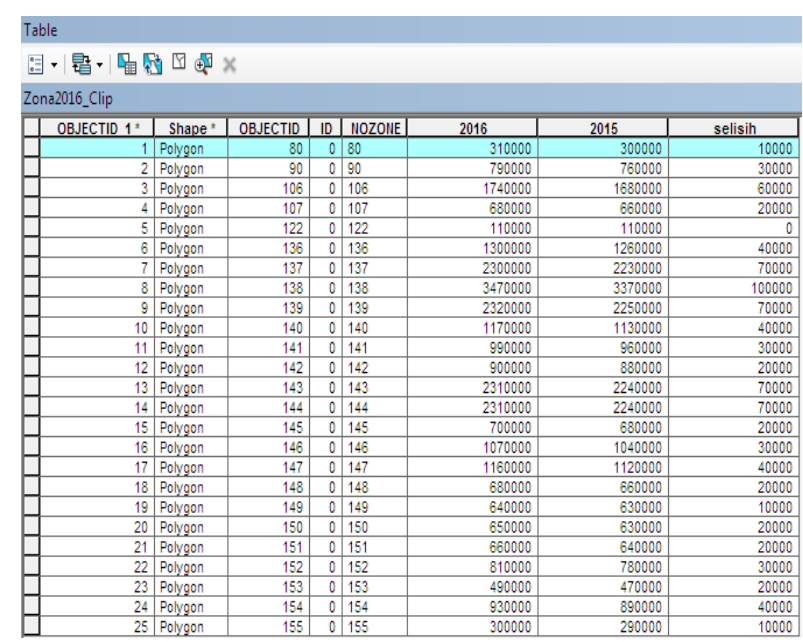

Gambar 6. Hasil Validasi Pada Perangkat SIG
File Edit Query Favourites Macros View Help

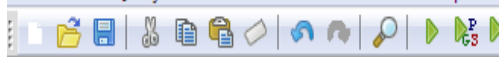
SQL Editor Graphical Query Builder Previous queries

SELECT nozona, znt16, znt15, selisi

FROM selisih

WHERE selisih > 70000;

\begin{tabular}{|c|c|c|c|c|c|c|}
\hline \multicolumn{7}{|c|}{ Dutput pane } \\
\hline \multicolumn{2}{|c|}{ Data Output } & Explain & \multicolumn{2}{|c|}{ Messages } & \multicolumn{2}{|c|}{ History } \\
\hline & $\begin{array}{l}\text { nozona } \\
\text { bigint }\end{array}$ & & $\begin{array}{l}\text { znt16 } \\
\text { integer }\end{array}$ & & & $\begin{array}{l}\text { selisih } \\
\text { integer }\end{array}$ \\
\hline 1 & 138 & & 3470000 & 33 & 0000 & 100000 \\
\hline
\end{tabular}

Gambar 7. Hasil Query Nilai Tertinggi Pada PostgreSQL

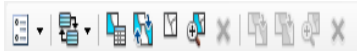

\begin{tabular}{|c|c|c|c|c|}
\hline Zonz2016_lip & & & & \\
\hline OBNECTID 11: & 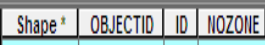 & 2016 & 2015 & selish \\
\hline & $\begin{array}{ll}138 & 0 / 138 \\
\end{array}$ & 340000 & 3370000 & 100000 \\
\hline
\end{tabular}

Gambar 8. Hasil Validasi Pada Perangkat SIG

c. Menampilkan zona yang tidak mengalami perubahan nilai tanah (lihat Gambar 9 dan 10)

\begin{tabular}{|c|c|c|c|c|c|}
\hline \multicolumn{6}{|c|}{ Edit Query Favourites $\mathrm{Ma}$} \\
\hline \multicolumn{6}{|c|}{ 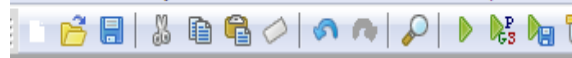 } \\
\hline \multicolumn{6}{|c|}{ SQL Editor Graphical Query Builder } \\
\hline \multicolumn{6}{|c|}{ Previous queries } \\
\hline \multicolumn{6}{|c|}{$\begin{array}{l}\text { SELECT nozona, znt16, znt15, selisih } \\
\text { FROM selisih } \\
\text { WHERE selisih = }\end{array}$} \\
\hline \multicolumn{6}{|c|}{ Output pane } \\
\hline \multicolumn{2}{|c|}{ Data Output } & Explain & Messa & His & \\
\hline & \multicolumn{2}{|c|}{$\begin{array}{l}\text { nozona } \\
\text { bigint }\end{array}$} & $\begin{array}{l}\text { znt16 } \\
\text { integer }\end{array}$ & $\begin{array}{l}\text { znt15 } \\
\text { integer }\end{array}$ & $\begin{array}{l}\text { selisih } \\
\text { integer }\end{array}$ \\
\hline 1 & \multicolumn{2}{|l|}{122} & 110000 & 110000 & 0 \\
\hline
\end{tabular}

Dari hasil query diatas dapat dilihat pada output panebahwa zona yang tidak mengalami perubahan nilai tanah pada tahun 2015 hingga 2016 adalah zona 122 dengan harga tetap sebesar Rp. 110.000,- pada masing-masing tahunnya.

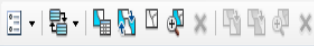

Zona2016_Clip
\begin{tabular}{|r|r|r|r|r|r|r|r|}
\hline OB.JECTID 1: & Shape $^{*}$ & OBJECTID & 10 & 110ZONE & 2016 & 2015 & selisih \\
\hline & 5 Polygon & 122 & 0 & 122 & 110000 & 110000 & \\
\hline
\end{tabular}

Gambar 10. Hasil Validasi Pada Perangkat SIG 


\section{KESIMPULAN}

Dari penelitian yang telah dilakukan, dapat diambil kesimpulan sebagai berikut :

1. Penelitian ini berhasil membuat basisdata spasial inventarisasi data nilai tanah. Basisdata yang telah dibuat dapat dijadikan sebagai data pendukung dalam mengidentifikasi perubahan nilai tanah di Kecamatan Tuban Kabupaten Tuban.

2. Terdapat perubahan nilai tanah di Kecamatan Tuban. Perubahan yang tertinggi terjadi pada zona 138 dengan perubahan sebesar $\mathrm{Rp}$ 100.000.- sedangkan zona yang tidak mengalami perubahan nilai tanah yaitu zona 122 dengan harga tanah tetap sebesar Rp 110.000.-

\section{DAFTAR PUSTAKA}

Egenhofer, M. J. 1994. Spatial SQL : A Query and Presentation Language. IEEE Transactions on Knowledge and Data Engineering 6 (1), 86-95.

Fathansyah. 2012. Basis Data Edisi Revisi.Bandung: INFORMATIKA.

Rajabidfard, A. d. 2000. Spatial Data Infrastructures: An Intitiative To Facilitate Spatial Data Sharing.Melbourne, Victorial: Spatial Data Research Group, Department of Geomatics, The University of Melbourne.

Sujarto, D. 1982. Nilai dan Harga Tanah dalam Pengembangan Wilayah. Bandung: Institut Teknologi Bandung.

Sunaryo. 2008. Peningkatan Integritas Basis Data Spasial PBB melalui Penerapan Enterprise Rule. Dipetik 5 17, 2015, dari Institut Teknologi Bandung:

http://digilib.itb.ac.id/files/disk1/633/jbptitbppgdl-sunaryonim-31629-3-2008ts-2.pdf

Sutanta, Edhy. 2011. Basis Data Dalam Tinjauan Konseptual. Yogyakarta: Andi Offset. 